\title{
ALGUNOS ASPECTOS DE LA LETRA DEL TANGO
}

Enrique P. Haba

I

Sobre el tango (1), y antes que nada a propósito de sus letras, se ha dicho de todo: ilo mejor y lo peor! No puede extrañar, desde luego, que el tango, como cualquier otro fenómeno estético, no se halle en condiciones de agradar a todo el mundo. Razones de educación, o el temperamento de cada uno, suelen dar cuenta de por qué determinadas expresiones artísticas consiguen Ilegarle o no a la gente. Menos justificado resulta, en cambio, que hasta personas de un apreciable nivel intelectual puedan deslizar, como si tal cosa, juicios en los cuales tienden a identificar letra de tango con mala literatura.

En el tango existen, por supuesto, letras de calidad muy menor. Es más, sin duda éstas se dan de manera abundante. Pero en tal orden de cosas, no se ve por qué ha de pedírsele al tango lo que nadie exige para ninguna otra rama del arte: que todas o la mayoría de las obras producidas merezcan ser rescatadas del olvido.

Es cierto que hay muchas malas letras de tango. $Y$ de ellas no hay por qué ocuparse. En cambio, cómo no admirar unas palabras de tango que nos dicen:

\author{
Vagos con halagos de bohemia mundanal, \\ pobres sin más cobres que el anhelo de triunfar, \\ ablandan el camino de la espera \\ con la sangre toda llena \\ de cortados (2) \\ en la mesa de algún bar.
}

(Homero Expósito, Tristezas de la calle Corrientes, 1942) (3).

No han de ser muchos, en el Río de la Plata, los capaces de escribir versos tan logrados. Sin embargo, tampoco sería justo generalizar demasiado sobre la base del ejemplo ofrecido. No toda ni la mayor parte de la literatura tanguera más valiosa presenta similares excelencias de elaboración en el tratamiento del lenguaje.

Existen letras que, no obstante ser muy buenas como tales, poco o nada tendrían que hacer fuera de su riguroso contexto tanguero. Cuando juzgamos el texto de un tango, nunca deberíamos perder de vista que sus palabras no han sido escritas para ser simplemente leídas o recitadas, sino que están destinadas a integrarse con la música respectiva y a ser presentadas por medio de una interpretación.

Valga una comparación, aunque sea gruesa. Si hubiera que abrir juicio sobre el valor arquitectónico de un edificio, no nos fijaríamos en una cosa sola. Tendríamos que apreciar una pluralidad de aspectos en conjunto: la forma, el decorado, la comodidad de los ambientes, la solidez de la construcción, etc. $\mathrm{Y}$ si procedemos a estimar alguno de esos elementos en particular, no nos bastaría con observarlo aisladamente, sino que trataríamos de ver en qué medida armoniza con el conjunto. Por ejemplo: para valorar allí la decoración de una pared, no emplearíamos los mismos tipos de criterio que si se trata de apreciar un cuadro presentado en una exposición (en este último caso, solo examinaríamos los valores de la pintura como tal, nada más).

Tratándose del tango-canción (4), también ahí la perspectiva adecuada es un enfoque que lleve a apreciar cada uno de sus elementos en función del conjunto. La letra, la música, la interpretación vocal e instrumental, constituyen un todo, conforman una "estructura" global, no una mera adición de partes que se aprehenden cada una por su lado. La letra es verdaderamente buena en la medida en que armoniza con todo lo demás. Cada elemento del conjunto se apoya en los otros, aparece realzado o disminuido por la interrelación que guarda con ellos.

Algunas letras (por ejemplo, Tristezas de la calle Corrientes) presentan caracteres tales que, incluso si las tomamos en forma aislada, en sí mismas, o sea, con independencia de la música y de la interpretación, asi y todo pueden esos textos resultar muy valiosos como literatura propiamente dicha. Mas hay otras letras que pierden la mayor parte de su valor si las aislamos de su música e interpretación tangueras. No quiere decir que estos otros textos no pueden alcanzar, también ellos, a ser excelentes. Lo serán si sirven para lograr, como ingredientes del conjunto, que este produzca un 
buen resultado estético como fenómeno artístico global.

Tirao por la vida de errante bohemio, estoy, Buenos Aires, anclao en París; curtido de malas, bandeado de apremio, te evoco desde este lejano país.

Contemplo la nieve que cae blandamente, desde mi ventana que da al bulevar; las luces rojizas con tonos murientes parecen pupilas de extraño mirar.

\section{(Enrique Cadícamo, Anclao en París, 1931)}

Estos versos tal vez no presentan, considerados en sí mismos, la riqueza de imágenes que mostraba el ejemplo anterior. Pero también ellos dieron lugar a un tango memorable... aunque es menos fácil darse cuenta si no nos ayuda el recuerdo de su versión por Carlos Gardel (5).

De cualquier manera, los dos fragmentos transcritos sirven, desde ya, para salirse al paso a una de las acusaciones más injustas que han caído sobre la literatura tanguera. Alguien lanzó la humorada de que el tango es "una crónica policial con guitarras". Otros, con menos ingenio pero con parecido tesón en hacer ver lo poco enterados que están, siguen repitiendo cosas por el estilo. Mas para cualquiera que se halle algo familiarizado con la historia del tango, no es un misterio que ese tipo de letras configura una minoría dentro del género. $Y$ aparecieron sobre todo en determinada época, por la década del 20.

No debería perderse de vista con tanta facilidad, además, uno de los principios elementales del conocimiento estético: en la obra de arte es tan fundamental el aspecto "formal", el tratamiento artístico, que en principio no existen temas "prohibidos". También ahí, los prejuicios son madre de generalizaciones falaces. Si el artista sabe manejar de modo adecuado su materia, siempre podrá elevarla al nivel de lo estético. No tiene sentido decretar a priori que será incapaz de hacerlo. Eso se verá... Y del mismo modo, inversamente: ningún tema, por sí mismo, es decir, por la sola fuerza de su contenido, tiene virtualidades que basten para hacerlo cuajar en calificada obra de arte, si no halla las manos hábiles que lo modelen para alcanzar ese punto (circunstancia que depende de muchos azares). La "forma" no es todo, por cierto, pero es ella la que transforma a la "materia" en expresión artística.

Hamlet y Macbeth son historias de crímenes.
Claro que no han pasado a ser hitos en la historia del arte por el mayor o menor número de muertes que cuentan, sino por la manera en que fueron contadas $y$ por el contexto literario en que se insertan esos asesinatos. También, salvando las distancias, cuando el tango recoge una historia sórdida puede hacer arte con ella. En todo caso, si el letrista se llama Homero Manzi:

\author{
Luz de locura \\ brilla en la oscura \\ mirada dura \\ del bailarín, \\ alcohol de añoranza \\ que al son de la danza \\ caliente venganza \\ debajo e' la crin. \\ Pobre morena, \\ brotó en sus venas \\ una serena \\ flor carmesí; \\ rencor en acecho, \\ pincel del despecho \\ pintando en tu pecho \\ la mancha carmín.
}

(Homero Manzi, Pena Mulata, 1941)

II

A esta altura podríamos preguntarnos si será cierto que, como dicen algunos, las letras de los tangos son de contenido tan variado que en ellas caben prácticamente todas las posibilidades temáticas principales que presenta la convivencia ciudadana en el Río de la Plata. La pregunta puede ser contestada de dos maneras. La primera de ellas tendría que ver no tanto con lo que ha sido la letra hasta ahora, sino que abarcaría incluso la que estaría habilitada para llegar a ser, en el presente o en un futuro próximo, por ciertas virtualidades (total o parcialmente inexploradas) que se consideran propias de este género. Se trata, pues, de arriesgar un pronóstico en cuanto a la posibilidad de creaciones nuevas dentro de un camino que seguiría siendo, de alguna manera, "tango". Por nuestra parte, sin embargo, nos contentaremos con esbozar algunas reflexiones que no exceden el marco de un segundo punto de vista: habremos de limitarnos a tratar de señalar lo que el tango ha conseguido abarcar efectivamente, hasta dónde llegaron sus letras en realidad.

Es justo admitir que esas letras lograron presen- 
tar una extensión bastante variada de asuntos y de formas estilísticas. Sería exagerado, empero, afirmar que no quedan igualmente sectores importantes sin explorar. $Y$ esto, tanto en lo que tiene que ver con la temática misma, como asimismo respecto a las diferentes posiciones subjetivas desde donde es posible enfrentar un determinado tipo de cuestiones. Sobre algunas de dichas carencias volveremos más adelante. De todos modos, no cabe desconocer que el tango supo vertir en clave estética muchos de los aspectos consustanciales a la vida en las ciudades del Río de la Plata. No corresponde intentar aquí una clasificación temática (6). Pero quisiéramos aludir rápidamente a algunas de aquellas cosas que, por su repetida inclusión en el tango, llegaron a asimilarse de tal modo a él, que configuran algo así como una "atmósfera" tanguera, un "clima" de acentuado sabor propio.

La radicación originaria del género, su localización en los arrabales rioplatenses de fines del siglo pasado y comienzos del actual, dejó huellas perdurables. Tanto es así que, todavía hoy, cuando han transcurrido años y años de su firme extensión a amplísimos sectores de las clases medias, no pocos piensan que la verdadera esencia del tango sigue indisoluble y exclusivamente vinculada a los sectores primitivos, más humildes, ligados a las orillas de la ciudad. Y lo cierto es que el patio del conventillo, el bailongo, las peleas de los guapos, el farol, el café de la esquina, etc., forman todo un mundo de típica raigambre tanguera, a menudo recreado magníficamente por las letras.

Farol de esquina, ronda y llamada, lengue y piropo, danza y canción, truco y codillo, barro y cortada, piba y glicina, fueye y malvón. Café de barrio, dato y palmera, negra y caricia, noche y portón, chisme de vieja, calle Las Heras, punga y silencio, Quinta Edición.

\section{Tango...}

fiera oscura voz de sangre.

Tango...

yugo amargo de arrabal.

Tango...

chata, pingo, luna grande.

Tango...

ibaile negro del puñal!

Tango...

voz cortada de organito;

\author{
guapo \\ recostado en el buzón; \\ trampa, \\ luz de aceite en el garito; \\ todo, \\ todo vive en tu emoción!
}

(Homero Manzi, Tango, 1942)

En muchos tangos, como el que acabamos de recoger, el enfoque está centrado más bien en el ambiente, en su colorido, no en la figura central de un protagonista. Se mencionan, sí, algunos personajes típicos; pero entonces ellos aparecen ubicados como un detalle más, otra figura colorida, dentro del panorama general. En otras obras, en cambio, pasa al primer plano un personaje, por sobre el telón de fondo ambiental. Podría ser traída aquí a colación toda una galería de tipos, pobladores intransferibles del barrio. Algunos los hemos visto ya asomar en los. versos recién transcritos. Otros son: el taita, el organillero, el compadrito, el tano, etc.

Ningún personajè fue recogido con tan repetida fruición por las letras como el de la milonguera, la muchacha de cabaret. El tango suele mostrarla ubicada en una etapa donde la protagonista ha caído ya en decadencia, o le presiente esa etapa como un sino indefectible. El tema fue tratado desde los más diversos ángulos. Desde la dulzura compasiva con que Linning mira a Milonguita, hasta el desprecio agresivo con que Celedonio Flores acusa a Margot, dos de las primeras letras del género; pasando por la descarnada amargura de Discépolo en Esta noche me emborracho, hasta llegar a la recreación que del personaje de Esthercita hace Expósito en Oro falso (un cuarto de siglo después de Linning). El siguiente ejemplo puede ser típico.

Te acordás, hermano, la rubia Mireya que quité en lo de Hansen al loco Cepeda; casi me suicido una noche por ella, y hoy es una pobre mendiga harapienta. Te acordás, hermano, lo linda que era, se formaba rueda pa' verla bailar...

Cuando por la calle la miro tan vieja, doy vuelta la cara y me pongo a llorar.

(Manuel Romero, Tiempos viejos, 1925)

Aunque dentro de la literatura tanguera son clásicas esas obras que se ubican en ambiente que 
no pueden ser sino rioplatenses, no hay que olvidar que abundan también las de otro tipo. En efecto, existe un alto número de letras cuya forma y cuyo contenido son, en cierto modo, de carácter más "universal", pero que igual han enaltecido la música popular rioplatense. Dentro de este rubro aflora, en primer plano, la enorme cantidad de páginas que tratan del amor. En todos los géneros de la literatura (teatro, poesía, novela, etc.), ese tema ocupa siempre una acentuada mayoría de la creación. El tango no podía escapar a la regla. Sin perjuicio de que, por supuesto, el tratamiento artístico ofrezca variantes, según los autores.

En muchas de tales letras, a pesar de lo universal del asunto, éste es presentado de una manera en que la tipicidad rioplatense resalta de inmediato. El efecto puede lograrse por dos vías. Una primera radica en el empleo de formas lingüísticas que pertenecen solo a las ciudades de la cuenca del Plata. Y una segunda, que con frecuencia aparece combinada con la primera, consiste en ubicar el relato entre personajes o ambientes cuyo cuño refleja también su peculiaridad rioplatense. Por el contrario, toda esa tipicidad deja de hacerse presente si el autor describe en forma más abstracta, esto es, cuando no usa sino vocablos estrictamente castellanos y sin traer a la escena ingredientes temáticos de señalado carácter local.

Dos ejemplos pueden servir para hacer patente esa posible diversidad de enfoques. Además servirán para comprobar, una vez más, la riqueza de estilos y de idiosincracias que diferencian entre sí a letras de distintos autores. Nada más lejos de la verdad que sostener, como a veces se escucha por ahí, que todos los tangos son iguales. Las dos obras que traeremos a título de ilustración, presentan en lo esencial un mismo tema, el de la tristeza ante la evocación del amor perdido. No obstante, son muy claras las diferencias en cuanto al estilo: el lenguaje y la actitud subjetiva, el temperamento con que el protagonista (quien relata su experiencia en primera persona) enfrenta la situación.

En primer término, pues, véase una letra de tendencia poética y universalista.

Acaso te llamaras solamente María, no sé si eras el eco de una vieja canción... pero hace mucho, mucho, fuiste hondamente mía sobre un paisaje triste, desmayado de amor.

El otoño te trajo mojando de agonía tu sombrerito pobre y el papado marrón; eras como la calle de la melancolía, que llovía, llovía, sobre mi corazón.

(Cátulo Castillo María, 1945)

Y de aquí el otro polo: actitud anti-romántica, lenguaje y protagonistas entroncados visceralmente en el arrabal.

Rechiflado en mi tristeza, hoy te evoco y veo que has sido en mi pobre vida paria solo una buena mujer; tu presencia de bacana puso calor en mi nido, fuiste buena, consecuente y yo sé que me has querido como no quisiste a nadie, como no podrás querer.

Hoy tenés el mate lleno de infelices ilusiones, te engrupieron los otarios, las amigas, el gavión; la milonga entre magnates con sus locas tentaciones, donde triunfan y claudican milongueras pretenciones, se te ha entrado muy adentro en el pobre corazón.

Nada debo agradecerte, mano a mano quemos quedado; no me importa lo que has hecho, lo que hacés y lo que harás.

Los favores recibidos, creo habértelos pagado, y si alguna deuda chica sin querer se me ha olvidado, en la cuenta del otario que tenés, se la cargás...

$Y$ mañana cuando seas descolado mueble viejo y no tengas esperanzas en el pobre corazón, si precisás una ayuda, si te hace falta un consejo, acordate de este amigo que ha de jugarse el pellejo pa' ayudarte en lo que pueda cuando llegue la ocasión.

Celedonio Esteban Flores, Mano a mano, 1928) 


\section{III}

Habíamos dicho que no es cierto que el tango haya tocado todos, o poco menos, los hilos de la problemática ciudadana rioplatense. Su repertorio de tipos y situaciones se quedó, por lo general, apresado en el corset de los primeros años del siglo. Es más, ni siquiera presenta una galería demasiado amplia de lo concerniente a esos años. La visión se mantuvo, en lo fundamental, limitada al enfoque de algunos de los aspectos que presentaban los suburbios de entonces.

El tango fue ganando luego nuevas capas de población para su causa. Amplió poco su temario, no obstante. Se limitó, para contemplar exigencias del nuevo público, a echar mano sobre todo a dos tipos de recursos. En el orden de los temas, aumentó el número de obras que se referían a conflictos sentimentales. Desencuentros que, en la óptica de los letristas, se presentaban como ocasionados, en la mayoría de los casos, ya por la falsía de la persona amada o simplemente su incomprensión, ya por el fatal transcurso del tiempo. Mientras que en el orden de lo formal, primero se fue restringiendo y después con frecuencia llegó a dejarse por completo de lado el uso de términos orilleros.

Bastó eso, en general, para satisfacer las apetencias del nuevo público. Este se sentía conforme con que se le hablara de conflictos de amor, tema que, por su universalidad, es accesible a todos. Pero además, paradójicamente, extensos sectores sentían asimismo como propias las acuarelas evocativas del arrabal de antaño, porque inyectaban un sentido de afirmación de nacionalidad a su gris existencia de clase media. Muchos de los términos arrabaleros, al principio esotéricos, habían pasado ya al dominio general; su uso ocasional, salpicando las letras, servía para dar el señalado tinte localista. Por el otro lado, un sector de público más intelectualizado, o que todavía pagaba tributo a viejas alergias antiorilleras, apreciaba las letras de más prolija elaboración formal y despojadas de vocablos localistas. Ni desde un ángulo ni desde el otro se sintió la necesidad de una verdadera renovación frente a la temática tradicional.

En particular, el tango nunca llegó a tocar, o lo hizo de manera accidental y no muy bien, la cuestión de las tensiones sociales (7). Es cierto que llegó Enrique Santos Discépolo, con sus letras formidables. En ellas, si bien se nota un intento por trascender del pequeño drama individual o tratar de presentarlo en tanto que movido por coordenadas sociales, lo cierto es que el resultado nunca logra ir más allá del grito de rebeldía individualista, frente a una sociedad ajena $y$ absurda, que nos oprime sin que nadie sepa muy bien por qué.

Discépolo tiene el mérito, por supuesto, de haber traído de alguna (nueva) manera lo social al tango. Sea como sea, nos muestra que cada hombre no es víctima solamente de su alternativa individual. Mas no se debería olvidar tampoco que, si este mérito alcanzó tan alta relevancia artística, ello fue en virtud, sobre todo, del talento expresivo extraordinario que Discépolo volcó en sus obras. No es un resultado que se desprenda de los meros temas, del hecho simplemente de traerlos a colación.

De todos modos, es indudable que la visión discepoliana de lo social presenta fuertes limitaciones. En esas letras no aparecen jamás tematizados los grandes tipos de conflicto que desde la base movilizan la dinámica de la sociedad, ni las fuerzas colectivas que ahí entran en acción. El absurdo y la infamia son elevados a la categoría de fuerzas metafísicas, necesarias, eternas, inexplicables e inextricables, consustanciadas con la esencia misma del hombre y del mundo: "el mundo fue y será una porquería...". Una visión anárquica y desolada, que solo el genio de Discépolo podía transformar, con tal validez artística, en tango.

Que el mundo fue y será una porquería, ya lo sé...

en el quinientos seis

y en el dos mil también; que siempre ha habido chorros, maquiavelos y estafaos, contentos y amargaos, valores y dublé; pero que el siglo veinte es un despliegue de maldá insolente ya no hay quien lo niegue, vivimos revolcaos en un merengue y en un mismo lodo todos manoseaos.

Hoy resulta que es lo mismo ser derecho que traidor... ignorante, sabio, chorro, generoso, estafador.

iTodo es igual!

iNada es mejor!

iLo mismo un burro 


\author{
que un gran profesor! \\ No hay aplazaos \\ ni escalafón, \\ los inmorales \\ nos han igualao. \\ Si uno vive en la impostura \\ y otro roba en su ambición, \\ da lo mismo que si es cura, \\ colchonero, rey de bastos, \\ caradura o polizón.
}

(Enrique Santos Discépolo, Cambalache, 1935)

Discépolo es, claro está, una cumbre en la letrística tanguera. A pesar de las limitaciones que le hemos señalado desde el punto de vista ideológico, no se puede cuestionar la superlatividad de sus obras desde el punto de vista artístico. Aqui viene bien recordar lo que decíamos, al principio, sobre la importancia de la forma en el fenómeno estético. Eso se ve más claro si comparamos los tangos de Discépolo con los que crearon otros autores, cuando estos quisieron desplazar su atención hacia lo social. Casi siempre fracasaron. Llegó a ocurrirle incluso a quienes, haciendo otros tipos de letra, son nombres ilustres dentro del género.

Tal el caso, bien significativo, de un autor que en su haber tiene nada menos que letras como Mano a mano. En efecto, alguna vez Flores trató de reflejar otro tipo de problemas. Así, tiene un tango que responde al plausible intento, excepcional dentro de la literatura tanguera, de presentar el drama que significa la desocupación para el obrero. Pero el autor no consigue, allí, dar con una tónica formal adecuada para la letra. No logra destilar su materia de lo toscamente melodramático.

Sus hijos no lloran por llorar,

ni piden masitas ni chiches

ni dulces, iSeñor! ...

Sus hijos se mueren de frío

y lloran hambrientos de pan.

La abuela se queja de dolor,

doliente reproche que hiere a su hombría;

también su mujer,

escuálida y flaca,

en una mirada

toda la tragedia

le ha dado a entender.

(Celedonio Esteban Flores, Pan, 1932)

El ejemplo es sintomático. En realidad, muy pocos tangos más intentaron transitar por estos caminos. $\mathrm{Y}$ cuando lo hicieron, justo es reconocer que el resultado no fue mucho mejor. Entre los más conocidos puede recordarse: Sentencia (del propio Flores), Al pie de la Santa Cruz (Mario Batistella), Acquaforte (Marambio Catán), etc. Pero tal inhabilidad congénita para abocarse de una manera más lograda a expresar lo social, no debería extrañarnos demasiado. En favor de esa limitación obran factores formales y sustanciales.

Los formales tienen que ver con las dimensiones externas de la letra, su extensión en palabras. De acuerdo con la extensión de la parte musical, también el texto es poco prolongado. Ocurre, en esto, algo similar a lo que acontece con los poemas, cuya extensión es por lo general mucho menor que la manejada para expresiones en prosa. También en el terreno de los poemas no ha solido cuajar cómodamente la temática centrada en materias de tipo social y político. La poesía ha mostrado mejor adecuación para expresar (bien) aspectos de índole más subjetiva, o lo descriptivo-sensorial, o ambos renglones conjugados. No es aquí lugar donde quepa indagar el por qué de esa dificultad que, para tratar cuestiones sociales, ofrecen esas formas que por esencia son relativamente breves, como los poemas propiamente dichos y las letras de tango. De cualquier manera, la experiencia enseña que muy pocas veces, en el marco de tales moldes, fueron creadas obras de alto valor estético centradas sobre cuestiones sociales.

Pero aparte de ese condicionamiento -negativo- desde el ángulo formal, decíamos que en el caso del tango intervienen además señalados factores -igualmente negativos - de naturaleza ideológica. Estos últimos consiguen explicarse bastante bien, a nuestro juicio, si se tiene en cuenta a qué tipo de público van destinados los tangos. La ideología de los creadores concuerda con la de aquellos para quienes producen esas obras. El letrista de tango, salvando peculiaridades individuales, tiene un concepto del mundo y de las cosas que es, en sus líneas más grandes y generales, el que tienen las capas más amplias de la sociedad rioplatense. Ha sido proverbial, en estas, su escasa comprensión de los problemas que atañen a la dinámica social de su entorno socio-económico. Lo mismo le ha sucedido al tango.

\section{IV}

De tiempo atrás, el hombre rioplatense ha podido darse cuenta de que algo anda mal. Pero no 
discierne con claridad qué, y mucho menos por qué. Además, no hay que perder de vista que siempre resulta difícil alcanzar a desprenderse de las maneras más habituales de pensar. Trasladado esto al terreno de los fenómenos artísticos, es claro que también en él cuesta muchísimo llegar a un acto de creación que subvierta las viejas formas y los viejos temas, o inclusive alcanzar uno que simplemente tenga la audacia de agregarles cosa nueva. Por lo demás, tendría que tratarse, para que esa renovación valga la pena, de cambios que den por resultado obras de cierta jerarquía.

El letrista de tango se acostumbró a pensar y a escribir de determinada manera. Pero tales modos están hoy, y ya lo estaban veinte años atrás, prácticamente agotados. Tampoco la sociedad es la misma de ayer, desde luego, aunque se sigan escuchando con gusto los viejos tangos o malos remedos más recientes. La vida se ha venido haciendo día a día más dura, incomprensiblemente. Tanto el hombre de la calle como el letrista comenzaron a encontrarse frente a la misma pregunta acuciante: ¿y ahora... qué? Ambos quisieran, acogotados por la inercia, seguir como antes. $\mathrm{O}$, mejor dicho, volver a lo de antes, que empero ya no puede ser lo de ahora. Y como no supieron cuáles son los caminos -sociales en un caso, artísticos en otro- para buscar una salida hacia adelante, se contentaron con volver nostálgicamente la cabeza hacia atrás. El paraíso es ayer.

Este siglo es de locura, de robot y escaparate, Buenos Aires sigue el ritmo de París y Budapest; todo el mundo se alza de hombros

y habla de la bomba $\mathrm{H}$...

iquiera Dios que no te cache una del Folies-Bergère!

Ríe el pobre, canta el rico, ronca el tano en su cotorro, se inventó el avión de chorro...

iy el chorro raja en avión! (8)

Viene Gina, se va Gina (9)

y de un pícaro planeta

un marciano en camiseta

baja en plato volador.

\section{$Y$ recostao pensativo}

contra el farol de una esquina, Juan Porteño (10) se santigua, mordiendo el pucho tristón; piensa acaso en la nostalgia

que aquella ciudad bajita

de románticas casitas

solo está en su corazón...

(Héctor Marcó, Juan Porteño, 1955)

En estos versos se refleja bien eso que Eduardo Adrián llamó una vez la "vocación por la nostalgia" del hombre rioplatense, rasgo que también es muy propio de sus gustos artísticos. Pero otra salida, más reciente, pudo apuntar en letras que Arturo Horacio Ferrer preparó para algunas músicas de Astor Piazzolla. En varias de ellas, aunque se rescatan temas tradicionales y hasta viejos términos orilleros, lo peculiar es que son integrados en una atmósfera de singular vaho irracionalista. En ese contexto, unos elementos tradicionales de la literatura tanguera son recogidos, sí, pero no tanto, esta vez para buscar un refugio en el paraíso perdido del pasado. Se trata, más bien, de envolver en el celofán de cierto color localista la presentación de un hoy, tal vez un siempre, donde la fruición por lo irracional aparece como en sentido más hondo y más vivo. El mundo del tango adquiere así un inusitado "contenido lúdico" (11), frente al cual una despreocupada locura individualista constituye la respuesta que nos sugiere Ferrer.

\section{Recitado:}

Las tardecitas de Buenos Aires tienen ese... qué se yo, ¿viste? Salís de tu casa por Arenales.... ilo de siempre!, en la calle y en vos. Cuando de repente, de atrás de un árbol, me aparezco yo. Mezcla rara de penúltimo linyera y de primer polizonte en el viaje a Venus, medio melón en la cabeza, las rayas de la camisa pintadas en la piel, dos medias clavadas en los pies y una banderita de taxi libre levantada en cada mano. iTe reís! ... pero solovos me ves; porque los maniquíes me guiñan, los semáforos me dan tres luces celestes y las naranjas del frutero de la esquina me tiran azahares. $Y$ así, medio bailando y medio volando, me saco el melón para saludarte, te regalo una banderita y te digo:

\section{Cantado:}

Ya sé que estoy piantao piantao, piantao... no vez que va la luna rondando por Callao, que un corso de astronautas y niños con un vals me baila alrededor... ibailá, vení, volá! Ya sé que estoy piantao, piantao, piantao... 
yo miro a Buenos Aires del nido de un gorrión, y a vos te vi tan triste... vení, volá, sentí el loco berretín que tengo para vos.

iLoco, loco, loco!... cuando anochezca en tu porteña soledad, por la ribera de tu sábana vendré con un poema y un trombón a desvelarte el corazón. iLoco, loco, loco! ... como un acróbata demente saltará sobre el abismo de tu escote hasta sentir que enloquecí tu corazón de libertad, iya vas a ver!

\section{Recitado:}

Vamos a volar, querida mía. Subite a mi ilusión super-sport y vamos a correr por las cornisas con una golondrina en el motor...

iViva, viva, viva! iLoca ella y loco yo! (Horacio Arturo Ferrer, Balada para un loco, 1969)

De todos modos, aunque en su momento esta obra registró un notorio éxito de difusión, en definitiva ella ha permanecido como ejemplo aislado; las restantes composiciones del binomio Piazzola-Ferrer tuvieron aceptación mucho más restringida. Los tangueros se han mostrado, en última instancia, fieles al otro tipo de páginas, más ajenas que la Balada a ciertas tendencias características de la canción "joven" que se vende en el mercado cosmopolita (en el Río de la Plata es lo que se conoce como "la Nueva Ola"). El "verdadero" tango sigue siendo, para el rioplatense, aquello que ese género produjo en la primera mitad del siglo, sobre todo. Asociado a esa época, tiempo feliz en el recuerdo, el tango funciona como símbolo de un vínculo, aún vivo, que nos ata sentimentalmente al pasado, a un cordón umbilical que no quisiéramos terminar de romper. El tango es memoria, podría decirse. Una memoria a la que los años le fueron aportando, cada vez más, la dimensión de mito.

Un amigo español me hacía notar, cierta vez, su asombro ante el hecho de que, en el Uruguay, sea tan corriente hallar en los hogares una foto de Gardel (12), mientras que es menos común encontrarse con una de Artigas (13). En efecto: isi el tango puede er nuestra Biblia, Gardel es Dios!
Pues para quien siente profundamente lo que es el tango, ahí no se trata de un fenómeno artístico más. No se admira a un gran creador de tangos, a Gardel, a Discépolo, a Troilo, de la misma manera en que admiramos a un sobresaliente actor de teatro o a un novelista excepcional. Es otra cosa... En materia de tango, suele haber algo más que la admiración por lo puramente artístico. Allí uno siente comprometida, de alguna manera, la propia personalidad. El tango nos expresa a nosotros mismos, en cuanto rioplatenses.

Los tangueros comprenden muy bien a qué nos estamos refiriendo. Pero quienes no están en la "pomada" de lo tanguero, por supuesto que no pueden alcanzar a percibirlo con la misma claridad. Sin embargo, estos apuntes hemos querido destinarlos ante todo a lectores que suponemos poco consustanciados con el tango. No con la pretensión de ofrecerles un verdadero panorama de lo que significa esa letrística en su conjunto, sino con la intención, apenas, de insinuar alguno que otro de los aspectos en que se exterioriza su polifacético mundo. Los ejemplos seleccionados no fueron elegidos, por lo demás, con vistas a tratar de brindar aquí una muestra de lo mejor que produjera dicho género. Quisimos antes bien intentar acercarnos a una visión realista de sus posibilidades, dar alguna idea de sus virtudes pero también de sus límites; no hemos vacilado, por eso, en presentar incluso obras de valía secundaria.

Cada modalidad de lo artístico tiene su "secreto", muy propio: una especie de "complicidad" que liga al artista con su público, que les permite comprenderse mutuamente. Un "secreto" que suele parecerle muy elemental y fácil a quienes lo comparten, pero que acaso se empeña, con mucha terquedad, en ocultar su clave a los que aún no se han habituado a dar con él. Es lo que ocurre con el tango.

Para aquellos lectores que no han penetrado en ese secreto $\tan$ rioplatense, y hasta para quienes piensen que ni siguiera hay tal, hemos querido tenderles un puente hacia él. Pero es del otro lado del puente que está, no hay que olvidarlo, lo más interesante: iel tango mismo! Son setenta años de historia, vivos en el disco, a los que todavía puede importar acercarse. Tratar de hacerlo, acaso implique un esfuerzo. Pero si el lector se decide a intentarlo, tal vez llegue a estar de acuerdo con nosotros en que bien vale la pena. 


\section{BIBLIOGRAFIA}

CARELLA, Tulio: El tango. Mito y Esencia. Ediciones Doble P. Buenos Aires, 1956.

CASULLO, Fernando Hugo: Diccionario de voces lunfardas y vulgares, Editorial Freeland, Buenos Aires, 1972.

GALASSO, Norberto: Discépolo y su época, Editorial Jorge Alvarez, Buenos Aires, 1967.

GOBELLO, José: Diccionario lunfardo: A. Peña Lillo Editor, Buenos Aires, 1975.

$\mathrm{HABA}$, Enrique P.: Esquema del tango (con principal referencia a la década del 40), 2 tomos, El Club de la Guardia Nueva, Montevideo, 1968.

LARA, Tomás y Leonilda RONCETTI DE PANTI, El tema del tango en la literatura argentina. Ediciones Culturales Argentinas, Buenos Aires, 1961.

MAFUD, Julio: Sociología del tango, Editorial Americalee, Buenos Aires, 1966.
PUGA, Boris: Carlos Gardel. Discografía, 2da. ed., El Club de la Guardia Nueva. Montevideo, 1970.

PUGA, Boris: El tango en los años cuarenta, El Club de la Guardia Nueva, Montevideo, 1972.

SABATO, Ernesto: Tango, discusión y clave. Con una antología de informaciones y opiniones sobre el tango y su mundo, realizada por T. DI PAULA, y Noemí LAGOS, Editorial Losada, Buenos Aires, 1963.

SOLARES, Jorge Ricardo: La obra poética de Homero Manzi, El Club de la Guardia Nueva, Montevideo, 1965.

VIDART, Daniel: El tango y su mundo, Ediciones Tauro, Montevideo, 1967.

VILARIÑO, Idea: Las letras de tango, Editorial Schapire, Buenos Aires, 1965.

\section{VOCABULARIO \\ (Términos rioplatenses típicos)}

Bacana: mujer bonita.

Bandeado: sobrepasado.

Berretín: "Afición desmedida hacia determinadas cosas, rayana ya en la manía" (Casullo); "Ilusión, esperanza acaraciada sin fundamento racional" (Gobello).

Cachar: coger.

Codillo: juego de naipes.

Compadrito: "Individuo de la plebe, pendenciero, jactancioso, afectado en la vestimenta y en su manera de conducirse" (Gobello).

Cortada: calle cortada.

Cortado: café, servido en una taza pequeña, al que se le agrega ("cortándolo") un poco de crema.
Cotorro: "Aposento, cuarto, especialmente si es de soltero" (Gobello).

Chata: carro plano, tirado por caballos; "Carro de cuatro ruedas, sin cubrir, que sirve para transportar cargas pesadas" (Gobello).

Chorro: ladrón.

Dublé: "Objeto de metal vil que imita una joya" (Gobello).

Engrupir: engañar.

Fueye: bandoneón.

Gavión: "Hombre, tipo, y en general, conquistador, donjuanesco" (Casullo); "Burlador, libertino, que seduce a las mujeres" (Gobello).

Lengue: pañuelo. 
Linyera: "Vagabundo que vive de lo que le dan o de lo que sustrae" (Gobello).

Mate: cabeza.

Milonguera: "bailarina contratada en lugares de diversión nocturna" (Gobello).

Otario: estúpido, tonto, imbécil.

Palmera: (estar o quedar en la...): "Estar sin dinero; en mala situación" (Casullo).

Piantao: loco, alguien que desvaría.

Piba: muchacha.

Pingo: caballo.

Punga: "Robo o sustracción de los objetos que la gente lleva en los bolsillos; ratería hecha con maña y audacia" (Casullo).
Rajar: huir.

Rechiflado: "Tener sorbido el seso por una persona o cosa" (Gobello).

Taita: "hombre prepotente y de coraje" (Casullo), el cual se impone en el arrabal.

Tano: italiano.

Truco: cierto juego de naipes, de típica raigambre popular.

\section{ADVERTENCIA:}

La mayoría de estas palabras registran más de una acepción. Pero aquí nos hemos limitado a destacar, para cada una de ellas, solo la acepción que mejor corresponde al sentido que la palabra indicada presenta dentro de los contextos donde aparece recogida en nuestro estudio.
(1) El presente estudio se limita al tango en cuanto expresión artística típica del Río de la Plata, esto es, de la cuenca cultural que forman el Uruguay y la Argentina. Se trata de un fenómeno que poco o nada tiene que ver con lo que bajo el mismo nombre, "tango", es producido a veces en otras latitudes (por ejemplo, en Europa). Más específicamente todavía, el tango es música ciudadana de Buenos Aires y de Montevideo; pero a partir de ahí, los argentinos y los uruguayos, de todas las regiones, lo reconocen como cosa representativa de lo rioplatense en general, como expresión típica de lo nacional para los países de ambas orillas del Plata.

(2) Señalamos mediante cursivas los términos típicos rioplatenses. Al final de este trabajo se encuentra un Vocabulario que indica el sentido de dichas palabras, para los contextos en que las recogemos.

(3) No tenemos la seguridad de que los versos transcritos correspondan en forma exacta al original de la obra en cuestión. Y esto vale también para las demás letras que serán incluidas a lo largo de nuestro trabajo. En ningún caso nos ha sido posible confrontarlas con los registros de la Sociedad de Autores. Las letras que presentamos, las recogimos de revistas o las hemos tomado directamente de la audición de discos comerciales. Ninguna de estas dos fuentes ofrecen entera garantía de fidelidad; máxime teniendo en cuenta que, con respecto a una misma página, a veces no faltan diferencias entre versiones grabadas por distintos intérpretes, o entre las que presentan distintas revistas, y por supuesto también entre unos y otros. De todos modos, las disimilitudes no suelen ser notables; en cada caso, cuando ellas se dan, hemos optado por seguir el texto que nos aparece el más logrado desde el punto de vista estético. La división en líneas, dentro de la letra, corresponde por lo general a las frases musicales; hemos determinado también la puntuación.

El año mencionado junto al título de cada obra, suele ser el de su primera grabación comercial. Cabe pensar que esta corresponde, con un buen grado de aproximación, al momento en que la página fue compuesta (presunción que hemos rectificado allí donde podemos disponer de datos fehacientes para probar que la obra es de data anterior). Las referidas fechas de grabación fueron obtenidas, en lo fundamental, con base en los trabajos del investigador uruguayo Boris Puga, cuyos detallados catálogos discográficos de tango, documentados con rigor poco común en la materia, constituyen una fuente de información invalorable (véase, p. ej., sus dos catálogos indicados en la Bibliografía).

Quiero asimismo expresar mi agradecimiento al coleccionista francés, con cuya amistosa colaboración conté para obtener datos necesarios durante la preparación del presente trabajo.

(4) Se suele llamar tango-canción al que presenta una letra. En cambio, se denomina tango instrumental al que no la tiene o es interpretado sin cantor, es decir, por conjuntos instrumentales solos. 
(5) Carlos Gardel fue el creador, a partir de 1917, de la modalidad cantable que se hizo clásica en el tango rioplatense. Gardel fue el primero, pero también el más eximio cantor de tangos. Muerto en un accidente de aviación (1935), en pleno augt de su carrera, él continúa constituyendo, aún hoy, el símbolo por excelencia de lo tanguero. Su popularidad no ha decrecido con el correr de los años; antes bien es un lugar común reconocer que "cada día canta mejor", más todavía si lo comparamos con los "cantores" que el tango-canción soporta a partir (sobre todo) de los años 60. Mediante la pervivencia que le aseguran sus discos, las páginas que Gardel populariza y su estilo interpretativo siguen siendo acogidos con admiración devota, por viejas y nuevas generaciones.

(6) Cf. el valiosísimo estudio de la profesora uruguaya Idea Vilariño, Las letras de tango, que presenta una enumeración muy completa de los "temas" y "motivos" que han aflorado en las letras.

El término "social" lo utilizaremos aquí sin mayor precisión, de acuerdo al sentido que ofrece en el lenguaje corriente.
(8) Tal vez se trata de una alusión a la huída del Presidente Perón de la Argentina, luego del golpe militar que lo derrocó en 1955.

(9) Alusión a la visita que la actriz cinematográfica italiana Gina Lollobrigida efectuara, por entonces, a la Argentina.

(10) Se le llama "porteño" al hombre de Buenos Aires. Juan Porteño viene a ser, así, el personaje-tipo que en esta letra es presentado como símbolo del porteño.

(11) Asi lo califica Rolando Cartategui, en un artículo que escribiera para la columna de El Club de la Guardia Nueva, publicado en el diario El popular de Montevideo: "La buena salud (económica) de un loco", en el Suplemento del citado diario, edición del 20 de feberero de 1970, p. 2.

(12) Ver supra, nota 5.

(13) José Gervasio Artigas (1764-1850) es el héroe máximo de la República Oriental del Uruguay. Se le considera el precursor de la independencia nacional, por sus históricas luchas contra españoles, porteños y portugueses.
El autor es consciente de los modestos alcances que tiene el estudio aquí recogido. Su versión original, que no llegó a ser publicada, data de hace unos cuantos años. Se trata de algo que estaba destinado, desde su origen, simplemente a "despertar el apetito" sobre el tema (para un análisis algo más ambicioso, cf. mi Esquema del Tango). El examen se detiene hacia finales de la década del sesenta -pero eso, habida cuenta de lo que en materia de tangos se hizo después, no estoy convencido de que sea una desventaja-.

El enfoque presentado es tributario de ciertos presupuestos en cuanto a criterios estéticos, sin que ellos aparezcan explicitados $-y$ menos aún fundamentados-- a lo largo de la exposición. Me refiero a lo que se diera en llamar "el Buen Tango", denominación destinada precisamente a distinguirlo del "tango" en general. En ese sentido, pero antes bien por razones del nivel de exigencia artística que por un mero desfase temporal, me he ubicado dentro de una tendencia de escasa actualidad. Por ejemplo, el cantor de tangos, quien en buena medida definió su perfil artístico en consonancia con aquellos criterios, está confinado a archivos de discos que acumulan el polvo de un cuarto de siglo, por lo menos. Aquellos que en la actualidad "cantan" (es un decir) los tangos, sean de antes o compuestos más recientemente, muestran tener mayor parentesco con el radioteatro y el cine comercial argentinos que con la tradición musical gardeliana. En un tiempo donde, divilización de transistores mediante, esos "cantores" están al día en eso de entender que ser "expresivo" quiere decir más o menos lo mismo que cultivar aparatosidades y acentuar la cursilería, resulta dudoso, claro está, si aquellos presupuestos pueden todavía alcanzar a ser comprendidos. Pero eso ocurre no solo en materia de tangos, sino a todo lo largo y lo ancho de nuestra atmósfera de televidentes.

El Buen Tango no tiene futuro, por lo menos a la vista. Desde luego, no tendría sentido tratar de limitarse a copiar, hoy, los modos y contenidos de la creación artística de antes; y es probable que ni siguiera se consiguiera hacerlo bien, aunque fuera intentado. El tango-canción que se presenta en la actualidad, sin embargo, no ofrece esta originalidad que la de llevar al paroxismo unos vicios que ya habían sido descubiertos por los intérpretes menos recomendables de los años 30 y 40 . Por lo demás, el echar recurso a ampulosidades y a toda clase de afectaciones, por no hablar de los desa- 
finamientos, ni siquiera constituye una invención de nuestro siglo. El mal gusto es casi tan viejo como el hombre mismo. En ese sentido, los intérpretes actuales se encuentran en ancha compañía, no solo en el espacio sino también en el tiempo.

El Buen Tango no dejó continuadores. Ni de carácter renovador, ni de los otros. Es un fenómeno del pasado. Constituye una estirpe agotada. De todos modos, si la validez de las producciones artísticas no se mide por la más reciente pulsación de un reloj de cuarzo, entonces puede aún tener sentido el abocarse a mostrar que la palabra "tango" llegó a designar también, alguna vez, cierta cosa bastante distinta a las gárgaras de telenovela que hoy nos sirven bajo dicho nombre. El objetivo del presente trabajo no puede ser otro que ese, el de contribuir a mantener viva la memoria de que tal cosa existió. 